Original article

\title{
Hospital admission of exposure to air pollution in Ahvaz megacity during 2010-2013
}

\author{
Mohammad Effatpanah ${ }^{\mathrm{a}}$, Hosein Effatpanah ${ }^{\mathrm{b}}$, Saeid Jalali ${ }^{\mathrm{c}}$, Iman Parseh ${ }^{\mathrm{d}}$, Gholamreza Goudarzi ${ }^{\mathrm{e}}$, \\ Gelavizh Barzegar ${ }^{\mathrm{d}}$, Sahar Geravandi ${ }^{\mathrm{f}}$, Fatemeh Darabi ${ }^{\mathrm{f}}$, Naser Ghasemian ${ }^{\mathrm{g}}$, \\ Mohammad Javad Mohammadi ${ }^{\text {h,* }}$ \\ a School of Medicine, Ziaeian Hospital, International Campus, Tehran University of Medical Sciences, Tehran, Iran \\ ${ }^{\mathrm{b}}$ Department of Public Health, Asadabad School of Medical Sciences, Asadabad, Iran \\ ${ }^{\mathrm{c}}$ School of Public Health, Ahvaz Jundishapur University of Medical Sciences, Ahvaz, Iran \\ ${ }^{\mathrm{d}}$ Behbahan University of Medical Sciences, Behbahan, Iran \\ ${ }^{\mathrm{e}}$ Air Pollution and Respiratory Diseases Research Center, Ahvaz Jundishapur University of Medical Sciences, Ahvaz, Iran \\ ${ }^{\mathrm{f}}$ Asadabad School of Medical Sciences, Asadabad, Iran \\ ${ }^{g}$ Department of Environmental Health Engineering, School of Public Health, Ahvaz Jundishapur University of Medical Sciences, Ahvaz, Iran \\ ${ }^{\mathrm{h}}$ Department of Environmental Health Engineering, School of Public Health AND Air Pollution and Respiratory Diseases Research Center, Ahvaz Jundishapur University of \\ Medical Sciences, Ahvaz, Iran
}

\section{A R T I C L E I N F O}

\section{Keywords:}

Hospital admission

Air pollution

Humans

Ahvaz

Iran

\begin{abstract}
A B S T R A C T
Introduction: Criteria air pollutants have been a serious problem for humans because of increased disease rates, treatment costs and death.

Objective: The aim of this study was to estimate the health endpoint of Ahvaz Megacity Criteria Air Pollutants (MCAP) in humans during 2010-2013. Criteria Air Pollutants (CAP) were monitored by Ahvaz Environmental Protection Agency (AEPA).

Methods: This study, evaluated the health effects which are related to particle mater $\left(\mathrm{PM}_{10}\right), \mathrm{Ozone}\left(\mathrm{O}_{3}\right)$, nitrogen dioxide $\left(\mathrm{NO}_{2}\right)$ and sulfide dioxide $\left(\mathrm{SO}_{2}\right)$ by descriptive analysis and AirQ model. Sampling according to EPA guideline was done and baseline incidence (BI) and relative risk (RR) measures by the World Health Organization (WHO) for Middle East region were used in order to estimate the health endpoint association of CAP.

Results: Result of this study is useful for better understanding of relationship between exposure to criteria air pollution and health effects. Hospital Admission (HA) were Hospital Admission Respiratory Disease (HARD), Hospital Admission for Chronic Obstructive Pulmonary Disease (HACOPD), Hospital Admission Cardiovascular Disease (HACD). According to the result of this study, the annual cases of hospital admission during 2010-2013 were $\left(\mathrm{PM}_{10}\right.$ : 3116, 3246, 3026 and 2895; $\mathrm{O}_{3:}$ 37, 42, 51 and 72; $\mathrm{NO}_{2:}: 10,13,21$ and 25; $\mathrm{SO}_{2:}$ 25, 31, 35 and 42), the average annual level of CAP in the same period were $\left(\mathrm{PM}_{10}\right.$ : 281.98, 288.38, 278.12 and 242.29; $\mathrm{O}_{3:}$ 66.52, 72.67, 102.27 and 223; $\mathrm{NO}_{2:}$ 28.7, 31, 37 and 41; $\mathrm{SO}_{2:}$ 78.92, 91.07, 92.75 and $112.3 \mu \mathrm{g} / \mathrm{m}^{3}$ ), respectively. Based on the results, the average of 4-year study was higher than NAAQS and WHO values. The concentration of exposure to criteria air pollutants can increased morbidity and mortality between residential in Ahvaz megacity. Conclusion: Results of our study can be very important for government, medical, public health and scientific. Also, this study can help to government for adoption of laws which are related to air pollution and achieve international air quality standards. Hence, it is necessary to reduce emission of criteria air pollution sat national management level.
\end{abstract}

\section{Introduction}

Nowadays, the most important agents that threaten the humans and environment in Iran are petroleum, gas, petrochemical, transportation, dust storm and population growth. ${ }^{1-14}$ Breathing of air pollutants can be induced different health endpoint. ${ }^{15-26}$ The effects of air pollution on

\footnotetext{
* Corresponding author. Department of Environmental Health Engineering, School of Public Health and Air Pollution and Respiratory Diseases Research Center, Ahvaz Jundishapur University of Medical Sciences, Ahvaz, Iran. Tel.: +989355439707; fax: +986133332015.

E-mail address: javad.sam200@gmail.com (M.J. Mohammadi).
} 
human health is one of the important issues that have addressed by several studies. Large studies conducted cities across the United States (U.S), Europe and in Asia reported of strong evidence about the deadly impact of air pollutants. Based on the result of these studies, risk of premature death increased with higher levels of criteria air pollutants. ${ }^{27-31}$ Short-term and long-term exposure to criteria pollutants can be disorders in respect with the function of large organs in body such as lung, eyes, brain, and heart.

Based on the result of different studies the main sources of emission and generation of criteria air pollutants in megacities are industries, economic development, domestic fuel burning, urbanization, transportation and vehicles. ${ }^{32-37}$ According to the result of several studies, the most important symptoms of criteria air pollutants increases hospital admission rates increase, coughing, reduced lung function, respiratory infections, coughing, asthma attacks, chronic obstructive pulmonary disease, eye irritation, increased respiratory and cardiovascular disease, heart stroke, respiratory and cardiovascular death in people region inhalation. ${ }^{35-62}$

Dockery et al. studied the relationship between exposure to criteria air pollutants and health endpoint. According to the result of this study cardiovascular mortality was independently associated with exposure to air pollutants. ${ }^{63}$ In similar works Zallaghi et al. and Mohammadi et al. studied the health endpoint in different cities in Iran caused by concentration of $\mathrm{PM}_{10} \cdot{ }^{64,65}$

Bell et al. studied the health endpoint due to exposure to ground level ozone (GLO). ${ }^{66}$ In 2004 Gryparis et al. studied the exposure to environmental GLO pollution sources and their health effects on human. ${ }^{55}$ In a similar work, Glad et al., in 2012 associated the relation between prevalence hospital admission and effects of gender and ethnicity with ambient ozone levels. ${ }^{67}$ Assessment of short term exposure to high GLO concentration and enhance rate of hospital admission caused repository and cardiovascular diseases on human which is conducted by Rich et al., in $2006 .^{68}$

Khaefi et al. studied $\mathrm{PM}_{10}$ effect on prevalence of COPD in Ahvaz, Khuzestan province of Iran during 2009-2013. ${ }^{8}$ Goudarzi et al., in 2016 evaluated the HARD related to $\mathrm{SO}_{2}$ on Ahvaz citizenship. ${ }^{17}$ In 2015 by Labelle et al., the evaluation of HARD and exposure to $\mathrm{SO}_{2}$ in industrial area in Quebec, Canada was done. ${ }^{69}$ Also, Lipmann et al. in Detroit, USA, studied the association of sulfur dioxide level and health effects on human. ${ }^{70}$ Tsai et al. studied the relationship between HARD and daily stroke admissions and $\mathrm{NO}_{2}$ in Kaohsiung, Taiwan. ${ }^{60}$ In another study by Zallaghi et al. the level of nitrogen dioxide in urban air was studied in order to assess the health of citizens of west and southwest cities of Iran. ${ }^{61}$

In the last decade development of heavy industries (petroleum, gas, oil, steel and pipe), dust phenomenon, climate change, annual rainfall reduction, rapid population growth, abundant waste production, lack of proper waste treatment systems and sewage are the most important risks that threaten the human, plant and animal environment. ${ }^{6,12,14,19,71-73}$ The purpose of this study was the potential effects of criteria air pollutants exposure assessment on hospital admission in Ahvaz megacity during 2010-2013.

\section{Methods}

\subsection{The study area}

This study is a descriptive and used model study. In this study was performed in 2010-2013 to estimate and correlate concentration of $\mathrm{PM}_{10}, \mathrm{O}_{3}, \mathrm{NO}_{2}$ and $\mathrm{SO}_{2}$ to hospital admission in Ahvaz megacity citizenship, Iran. Air Q model and Excel are used for processing, analysis and number of hospital admission caused by exposure to criteria air pollutants.

Evaluation to health endpoint of $\mathrm{PM}_{10}, \mathrm{O}_{3}, \mathrm{NO}_{2}$ and $\mathrm{SO}_{2}$ exposure was done by relative risk (RR), baseline incidence (BI) and attributable proportion (AP). The part of health endpoint which can be related to the criteria air pollutants exposure in Ahvaz megacity residential is the attributable proportion implies and in baseline incidence was divided to $10^{5.74,75}$ In the parameter screen, AP was calculated regarding to concentration of criteria air pollutants, BI and RR. Based on studied event incidence in the population in its place as the baseline is defined Baseline Incidence (BI). ${ }^{76}$ The baseline incidence was calculated, using Equation (1)

$B I=\frac{S U M\{[R R(c)-1] \times p(c)\}}{S U M[R R(c) \times p(c)]}$

Where: $p(c)$ is the proportion of Ahvaz population in category c of exposure and $\mathrm{RR}(\mathrm{c})$ is the relative risk for category $\mathrm{c}$ of exposure. It is a very useful to know the association between a disease and an environmental factor under study. Amount of RR was calculated as following formula ${ }^{77-79}$ :

$R R=\frac{\text { Incidence in the exposed population }}{\text { Incidence in the non exposed population }}$

\subsection{Geographical features of Ahvaz}

Ahvaz is a city with an area of 185 square kilometers that is the capital of Khuzestan Province (Southwest of Iran and Northern of Persian Gulf) in Iran and is located at $31^{\circ} 20^{\prime} \mathrm{N}$ and $48^{\circ} 40^{\prime}$ E. . $^{3,6,8,11,14}$ Ahvaz with an area of 140 square kilometers and a population of approximately 1.3 million is one of the megacities of Iran. Location of station in Ahvaz are presented Fig. 1.

\subsection{Data collection}

We, in this study was correlate the concentration of $\mathrm{PM}_{10}, \mathrm{O}_{3}, \mathrm{NO}_{2}$ and $\mathrm{SO}_{2}$ to Hospital Admission (HA) during the period 2010-2013. According to the report of International Classification of Diseases (ICD10), the number of hospital admission (HA) included: Hospital Admission Respiratory Disease (HARD- J44.8), Hospital Admission for Chronic Obstructive Pulmonary Disease (HACOPD- J44.1), asthma attacks (AA- J44) and Hospital Admission Cardiovascular Disease (HACDI51.6), diagnosed by emergency doctors ${ }^{80}$ and was estimated by Air-Q model (baseline incidence, relative risk and attributed proportion). Meteorological phenomenon occurs when a strong wind blows loose sand and dirt from a dry surface in arid and semi-arid regions is defined as a dust storm. ${ }^{81}$

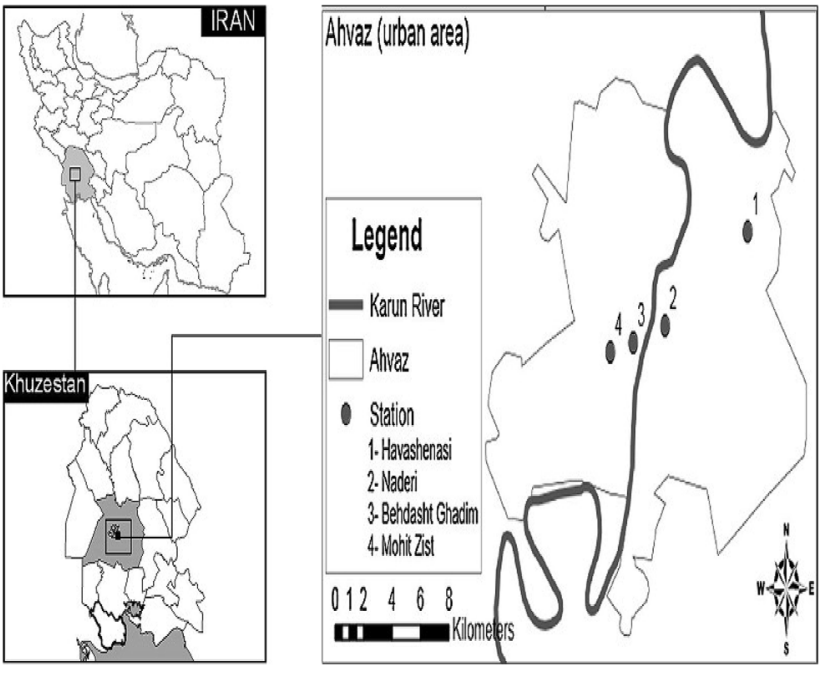

Fig. 1. Located of sampling stations in Ahvaz megacity. 
Table 1

Criteria air pollutants concentrations $\left(\mu \mathrm{g} / \mathrm{m}^{3}\right)$ and cases of hospital admission assessment of CAP on Ahvaz megacity inhabitants, $2010-2013$.

\begin{tabular}{|c|c|c|c|c|}
\hline Year & air pollutants & Annual mean & $\mathrm{RR}$ & HA (AP) \\
\hline \multirow[t]{4}{*}{2010} & Particle mater & 281.98 & $\mathrm{RR}=1.0044(1-1.0049)$ & 3116 \\
\hline & Sulfide dioxide & 78.92 & $\mathrm{RR}=1.01(1.006-1.014)$ & 25 \\
\hline & Ozone & 66.52 & $\mathrm{RR}=1.0080(1.004-1.012)$ & 37 \\
\hline & Nitrogen dioxide & 28.7 & $\mathrm{RR}=1.0038(1.0004-1.0094)$ & 10 \\
\hline \multirow[t]{4}{*}{2011} & Particle mater & 288.38 & $\mathrm{RR}=1.0044(1-1.0049)$ & 3246 \\
\hline & Sulfide dioxide & 91.07 & $\mathrm{RR}=1.01(1.006-1.014)$ & 31 \\
\hline & Ozone & 72.67 & $\mathrm{RR}=1.0080(1.004-1.012)$ & 42 \\
\hline & Nitrogen dioxide & 31 & $\mathrm{RR}=1.0038(1.0004-1.0094)$ & 13 \\
\hline \multirow[t]{4}{*}{2012} & Particle mater & 278.12 & $\mathrm{RR}=1.0044(1-1.0049)$ & 3026 \\
\hline & Sulfide dioxide & 92.75 & $\mathrm{RR}=1.01(1.006-1.014)$ & 35 \\
\hline & Ozone & 102.27 & $\mathrm{RR}=1.0080(1.004-1.012)$ & 51 \\
\hline & Nitrogen dioxide & 37 & $\mathrm{RR}=1.0038(1.0004-1.0094)$ & 21 \\
\hline \multirow[t]{4}{*}{2013} & Particle mater & 242.29 & $\mathrm{RR}=1.0044(1-1.0049)$ & 2895 \\
\hline & Sulfide dioxide & 112.3 & $\mathrm{RR}=1.01(1.006-1.014)$ & 42 \\
\hline & Ozone & 223 & $\mathrm{RR}=1.0080(1.004-1.012)$ & 72 \\
\hline & Nitrogen dioxide & 41 & $\mathrm{RR}=1.0038(1.0004-1.0094)$ & 25 \\
\hline Total Average & Criteria air pollutants & 129.24 & - & 792.93 \\
\hline
\end{tabular}

RR: is a ratio of the probability of the event occurring in the exposed group versus a non-exposed group.

AP: is defined as the part of health effects which can be attributed to the pollutant exposure in population.

\subsection{Ethical considerations}

Air Q model and Excel were used for analysis, sampling and data collection.

\section{Results}

The results of criteria air pollutants concentrations and cases of hospital admission are presented for each pollutants in Table 1. As it has shown in Table 1 the trend for yearly concentration of criteria air pollutants and number of hospital admission were decreased in Ahvaz megacity during 2010-2013.

During the time of study, concentration of criteria air pollutants $\left(\mathrm{O}_{3}\right.$, $\mathrm{PM}_{10}, \mathrm{SO}_{2}$ and $\mathrm{NO}_{2}$ ) were higher in 2010 than in 2013. Also, among criteria air pollutants $\mathrm{PM}_{10}$ has the greatest impact on the Number of hospital admission. Calculated number of cases were related to $\mathrm{O}_{3}$, $\mathrm{PM}_{10}, \mathrm{SO}_{2}$ and $\mathrm{NO}_{2}$ at central RR (1.0080, 1.0044, 1.010 and 1.0038) during 2010-2013. Central RR can be a reasonable indicator of current situation in view of criteria air pollutants health effects.

As Fig. 2 indicates, $\mathrm{PM}_{10}$ and $\mathrm{NO}_{2}$ were the highest and the lowest concentration between criteria air pollutants during 2010-2013. A downward trend is observed in $\mathrm{PM}_{10}$. Rising trend of concentrations was observed about $\mathrm{SO}_{2}, \mathrm{O}_{3}$ and $\mathrm{NO}_{2}$ pollutant (Fig. 2).

Cumulative number of hospital admission cases related to criteria air pollutants during 2010-2013 illustrated in Fig. 3.

Based on the result of Fig. 3, year of 2011 had the maximum number of HA and year of 2013 had the minimum number of HA attributed to CAP in the period of study.

Average concentrations of criteria air pollutants during 2010-2013 illustrates in Fig. 4. It should be noted that box plot shows the minimum, quarter ${ }_{1}$, median, quarter ${ }_{3}$ and maximum concentrations of $\mathrm{PM}_{10}, \mathrm{SO}_{2}, \mathrm{O}_{3}$ and $\mathrm{NO}_{2}$. Based on Fig. 4, level of $\mathrm{PM}_{10}$ is higher than another criteria air pollutants.

\section{Discussion}

Nowadays criteria air pollutants cause many complications on humans and the environment. In this study, HA of exposure to $\mathrm{PM}_{10}, \mathrm{O}_{3}$, $\mathrm{NO}_{2}$ and $\mathrm{SO}_{2}$ was evaluated by Air Q model in Ahvaz megacity inhabitants, Iran. Emission CAP especially $\mathrm{PM}_{10}$ increase of health effects between inhabitants because of paying attention to decreasing emission air pollutant is very vital. According to the result our study, the number

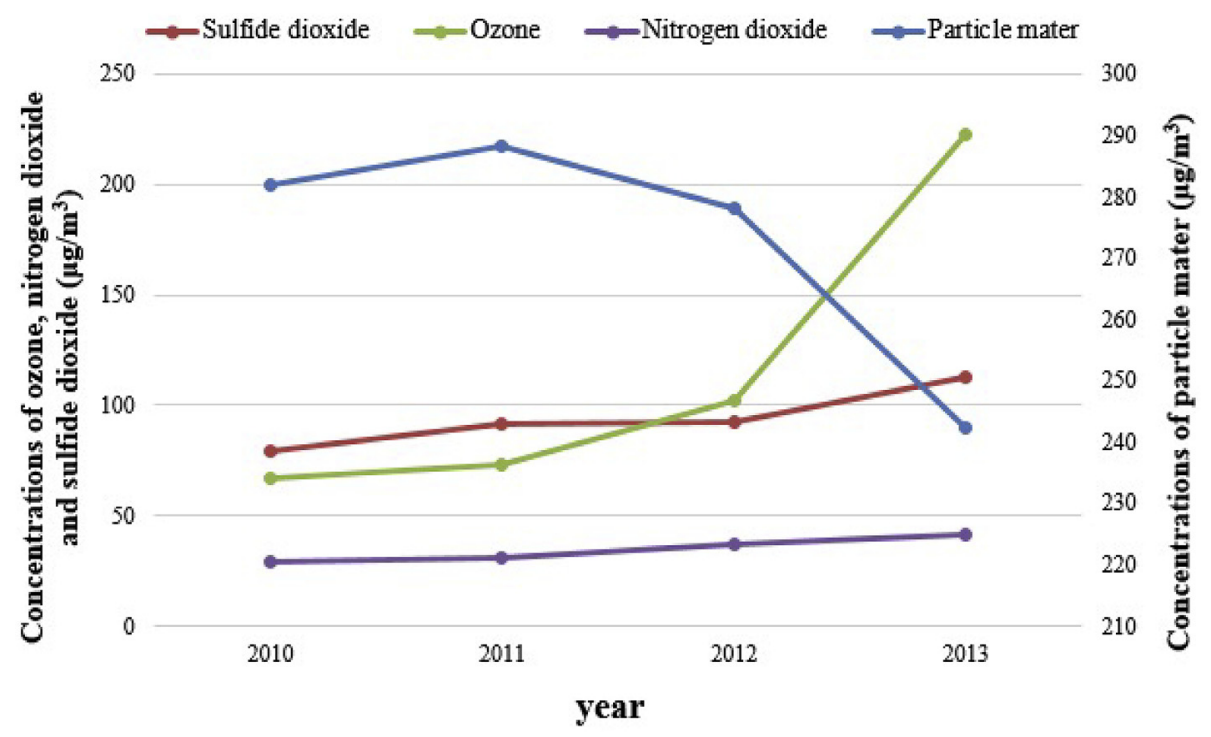

Fig. 2. Trend of concentrations criteria air pollutants in Ahvaz megacity, southwest of Iran, during 2010-2013. 

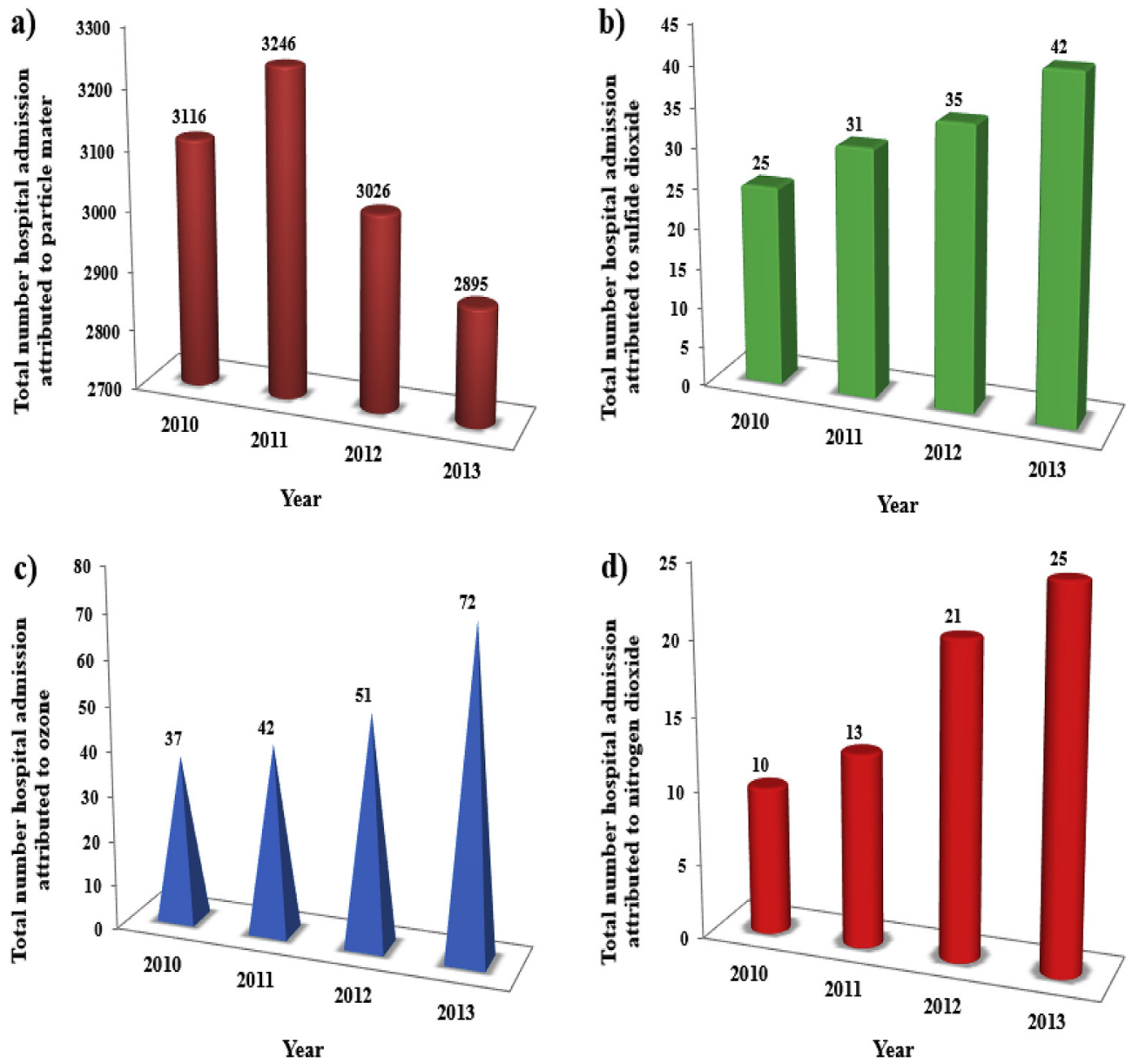

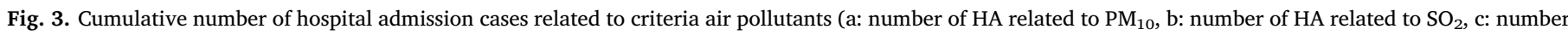
of $\mathrm{HA}$ related to $\mathrm{O}_{3}$, d: number of $\mathrm{HA}$ related to $\mathrm{NO}_{2}$ ).

of HA attributed to particle mater, ozone, nitrogen dioxide and sulfide dioxide in 2010 (3116, 37, 10 and 25), 2011 (3246, 42, 13 and 31), 2012 (3026, 51, 21 and 35) and 2013 (2895, 72, 25 and 42), respectively; in which the maximum was 2011 due to the highest concentration of PM10 among these years and CAP. According to the result of this study, the yearly average CAP concentrations during the same period were $\mathrm{PM}_{10}$ : 281.98, 288.38, 278.12 and 242.29; $\mathrm{O}_{3:}$ 66.52, 72.67, 102.27 and 223; $\mathrm{NO}_{2:}$ 28.7, 31, 37 and 41; $\mathrm{SO}_{2:}$ 78.92, 91.07, 92.75 and $112.3 \mu \mathrm{g} / \mathrm{m}^{3}$, respectively. According to the result of this study, the average concentration of criteria air pollutants was higher than region standard and WHO guidelines values. The trend of concentrations criteria air pollutants and number of hospital admission in the period of study in Ahvaz megacity presented in Table 1. Result our study showed that the number of HA related to $\mathrm{PM}_{10}$ during 2010-2013 was decreased and another CAP were increase; this can be due to decreases in concentration of $\mathrm{PM}_{10}$ and increase level of $\mathrm{O}_{3}, \mathrm{NO}_{2}$ and $\mathrm{SO}_{2}$.

Fig. 4 depicts box plot concentrations of criteria air pollutants during 2010-2013. The high concentration of CAP can be the result of production of development of transportation facilities and industrial processes and dust storm in recent years. The same results were found for CAP which were 2-3 times higher than the WHO guideline value. High concentration of measured criteria air pollutants in this study was associated with high number of hospital admissions in Ahvaz megacity inhabitants of Iran during 2010-2013.

Burnett et al. studied preliminary analysis of $\mathrm{PM}_{10}$ and possible hospital admissions to humans in Toronto, Canada. They reported that exposure to $\mathrm{PM}_{10}$ can caused increase $40.4 \%$ of hospital admissions on citizenship. ${ }^{82}$ Geravandi et al., in 2015 studied hospital admissions and exposure of them to $\mathrm{PM}_{10}$. According to the result of this study, approximately $4.1 \%$ of hospital admissions was happened when the $\mathrm{PM}_{10}$ concentration was over $20 \mu \mathrm{g} / \mathrm{m}^{3.83}$ In a similar work Zalaghi et al., in 2010 were investigated health impacts of air pollution in Ahvaz, Bushehr and Kermanshah, Iran. They showed that 5.1\%, 2.7\% and $1.9 \%$ of hospital admissions in Ahvaz, Kermanshah and Bushehr were happened when $\mathrm{PM}_{10}$ concentration was over $20 \mu \mathrm{g} / \mathrm{m}^{3}$ 65. The results of this study showed that concentration of $\mathrm{PM}_{10}$ in Ahvaz was very higher in compared to standards that the most reasons of this issue can be dust storm.

In 2000, Lippmann et al. in USA, studied the health effects of exposure to sulfur dioxide. Based on their result, levels of exposure showed a meaningful association between $\mathrm{SO}_{2}$ and health endpoint on human. Also, they reported the increase of $10 \mu \mathrm{g} / \mathrm{m}^{3}$ in $\mathrm{SO}_{2}$ was associated with an increase of $2 \%$ in hospital admissions. ${ }^{70}$ Results of our study are very higher in compared with these studies because of being heavy industries in Ahvaz megacity.

In another study in 6 Italian cities, Biggeri et al. reported a significant relationship between $\mathrm{SO}_{2}$ and health effects on citizenship. It was observed that an increase of $10 \mu \mathrm{g} / \mathrm{m}^{3}$ in sulfur dioxide was associated with an increase of $2.4 \%$ in hospital admissions. ${ }^{84}$

Existing heavy industries and high sulfur dioxide emitters particularly in winter can be related to high percentage of the hospital admissions in Ahvaz.

In a similar work Glad et al. studied the health endpoints of ambient ozone concentrations on human. According to the result of this study, the increase of each $20 \mu \mathrm{g} / \mathrm{m}^{3}$ GLO can increase $2.5 \%$ the hospital admission. ${ }^{67}$ In 2004, Bell et al. studied relationship between GLO and health endpoint in 95 megacities of U.S. They reported that exposure to GLO could be increased risk to human health such as hospital 
a)

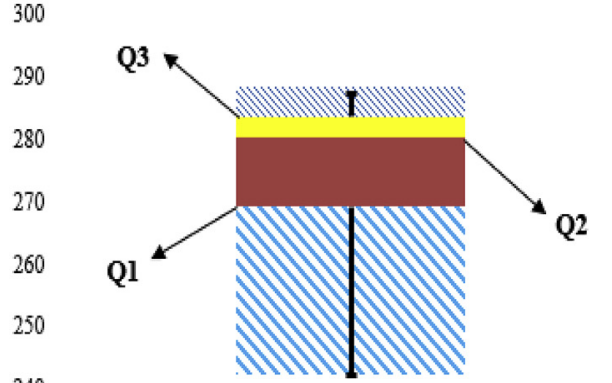

240

230

220

210

Particle mater

c)

200

150

100

50 b)

120

100

80

40

20

d)

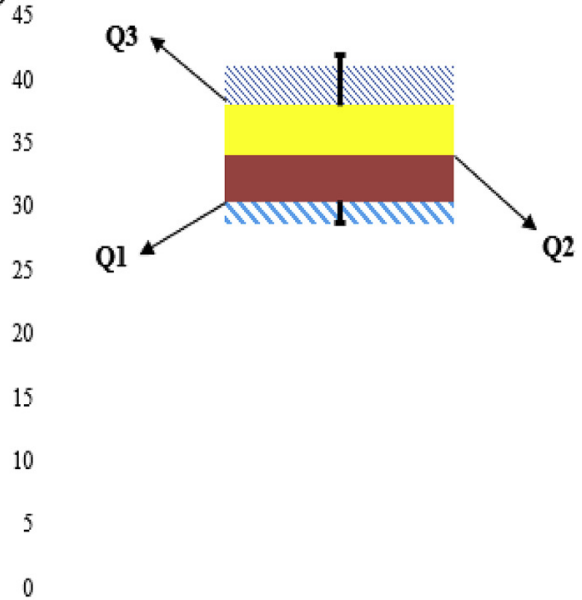

Nitrogen dioxide

Sulfide dioxide

Ozone

Fig. 4. Box plot concentrations of criteria air pollutants $\left(\mu \mathrm{g} / \mathrm{m}^{3}\right)$ during $2010-2013$.

admissions and daily deaths (10-ppb increase in level of GLO was related to a $0.52 \%$ increase in daily deaths). ${ }^{66}$ Shavrina et al. in their study found that there is a significant relationship between exposure to GLO and hospital admission's increase and respiratory diseases. ${ }^{85}$ This result is similar to result our study. Grypariset al studied the relation between health endpoints of ground level ozone in 23 European cities. They demonstrated that there is significant relationship between the increase level of ozone and number of hospitalization, repertory and cardiovascular disease (increase $10 \mu \mathrm{g} / \mathrm{m}^{3}$ level of GLO was associated with a $0.45 \%$ and $1.13 \%$ in the number of cardiovascular and respiratory deaths). ${ }^{55}$ Differences in geographic, demographic, and climate characteristics are the main reasons compared with ours results in this study.

In 2003 Tsai al studied the relation between nitrogen dioxide and health effects in Taiwan. They found that there is a relation between exposure to $\mathrm{NO}_{2}$ and hospital admission in Kaohsiung, Taiwan. ${ }^{60}$ Findings were shown that a $10 \mu \mathrm{g} / \mathrm{m}^{3}$ increase in levels of nitrogen dioxide was related to an increase of $2.5 \%$ in hospital admission. ${ }^{60}$ In another study conducted in West and Southwest Cities of Iran, there was a relation between nitrogen dioxide levels and health effects. ${ }^{61}$ According to their results, approximately $3.4 \%$ in Kermanshah, and $2.1 \%$ of number of hospital admission were related to nitrogen dioxide. ${ }^{61}$ Result of this study showed that number of hospital admission was higher because of people who are living in Ahvaz megacity had the higher exposure with $\mathrm{NO}_{2}$ compare to above area.

\subsection{Limitations and strengths}

The major limitations of this study were the usage of coefficient RR and BI (reported by WHO) related to hospital admission. Shortcomings in Iranian health registry system, was the biggest problem in accurate estimation of health effects resulting from exposure to air pollutants in this study. In order to solve registry problem, epidemiologic studies and long-term cohort studies are needed for calculate RR and BI specifically for this area.

\section{Conclusion}

Increase of the number of hospital admission and another health effects related to criteria air pollutants between citizen and paying attention to decreasing emission and concentration of this pollutants is very important. Based on the results of this study, level of CAP was higher than the WHO guideline value. Climate change, emissions from transportation, heavy industries (petroleum, oil, gas and steel), demographic and dust storm are the most important factors that have created adverse weather conditions and a high concentration of criteria air pollutants in Ahvaz megacity, Iran.

Development of green spaces, actions to reduce emissions to air in industries, using green fuels, decreasing particles in source at neighboring countries, application of modern automobiles, implementing appropriate health measures and careful monitoring are the best 
activities that will have important roles in decreasing the amount of criteria air pollutants.

\section{Funding/support}

This work was financially supported by grant (95s60 and 95s82): from Vice- Chancellor for research Affairs of Ahvaz Jundishapur University of Medical Sciences.

\section{Declaration of competing interest}

No potential conflict of interest was reported by the authors.

\section{Acknowledgement}

The authors would like to thank student Research Committee, Ahvaz Jundishapur University of Medical Sciences for providing financial supported by the grant: ( $95 \mathrm{~s} 60$ and $95 \mathrm{~s} 82$ ) of this research.

\section{References}

1. Davar H, Taghavirad SS, Mohammadi MJ. The investigation of effects of silica on the environment and prevention of release of the silica particles with simulation of gassolid flow in a gas cyclone Research. J Chem Environ. 2014;18:28-30.

2. Dobaradaran S, Geravandi S, Goudarzi G, et al. Determination of cardiovascular and respiratory diseases caused by PM10 exposure in Bushehr. J Mazandran Univ Med Sci. 2013;26:42-52 2016.

3. Geravandi S, Goudarzi GR, Vousoghi Niri M, Mohammadi Mj, Saeidimehr S, Geravandi S. Estimation of the cardiovascular and respiratory mortality rate resulted from exposure to sulfur dioxide pollutant in ahvaz. J Environ Stud. 2015;41:341-350.

4. Geravandi S, Sicard P, Khaniabadi YO, et al. A comparative study of hospital admissions for respiratory diseases during normal and dusty days in Iran. Environ Sci Pollut Control Ser. 2017:1-8.

5. Goudarzi G, Daryanoosh S, Godini H, et al. Health risk assessment of exposure to the Middle-Eastern Dust storms in the Iranian megacity of Kermanshah. Public Health. 2017;148:109-116.

6. Goudarzi G, Geravandi S, Foruozandeh H, et al. Cardiovascular and respiratory mortality attributed to ground-level ozone in Ahvaz, Iran. Environ Monit Assess. 2015;187:1-9.

7. Hashemzadeh B, Idani E, Goudarzi G, et al. Effects of PM 2.5 and NO 2 on the 8isoprostane and lung function indices of FVC and FEV 1 in students of Ahvaz city, Iran. Saudi J Biol Sci. 2019;26(3):473-480.

8. Khaefi Mehran GS, Ghasem Hassani, Ahmad Reza Yari, et al. Khaniabadi Yusef Omidi association of particulate matter impact on prevalence of chronic obstructive pulmonary disease in ahvaz, southwest Iran during 2009-2013. Aerosol Air Qual Res. 2017;17:230-237

9. Khaniabadi YO, Daryanoosh SM, Amrane A, et al. Impact of Middle eastern dust storms on human health. Atmos Pollut Res. 2017;8:606-613.

10. Khaniabadi YO, Daryanoosh SM, Hopke PK, et al. Acute myocardial infarction and COPD attributed to ambient SO2 in Iran. Environ Res. 2017:156:683-687.

11. Neisi A, Albooghobeish M, geravandi s, Mohammadi MJ, Torabpour M, Hashemzadeh B. Association of anesthetic toxic isoflurane gases of the indoor air of operating room, Ahvaz, Iran during. Toxin Rev. 2016;36:141-146.

12. Neisi A, Goudarzi G, Akbar Babaei A, et al. Study of heavy metal levels in indoor dust and their health risk assessment in children of Ahvaz city, Iran. Toxin Rev. $2016 ; 35: 16-23$

13. Soleimani Z, Goudarzi G, Naddafi K, et al. Determination of culturable indoor airborne fungi during normal and dust event days in Ahvaz, Iran. Aerobiologia. 2013;29:279-290.

14. Yari AR, Goudarzi G, Geravandi S, et al. Study of ground-level ozone and its health risk assessment in residents in Ahvaz City, Iran during 2013. Toxin Rey. 2016;35:201-206

15. Volkamer R, Jimenez JL, San Martini F, et al. Secondary organic aerosol formation from anthropogenic air pollution: rapid and higher than expected. Geophys Res Lett. 2006;33.

16. Gurjar B, Butler T, Lawrence M, Lelieveld J. Evaluation of emissions and air quality in megacities. Atmos Environ. 2008;42:1593-1606.

17. Goudarzi G, Geravandi S, Idani E, et al. An evaluation of hospital admission respiratory disease attributed to sulfur dioxide ambient concentration in Ahvaz from 2011 through 2013. Environ Sci Pollut Control Ser. 2016;23:22001-22007.

18. Goudarzi G, Idani E, Alavi N, et al. Association of polycyclic aromatic hydrocarbons of the outdoor air in Ahvaz, southwest Iran during warm-cold season. Toxin Rev. 2017:1-8.

19. Khaefi M, Goudarzi G, Yari AR, et al. An association between ambient pollutants and hospital admitted respiratory cases in Ahvaz, Iran. Fresenius Environ Bull 2016;25:3955-3961.

20. Khaniabadi YO, Fanelli R, De Marco A, et al. Hospital admissions in Iran for cardiovascular and respiratory diseases attributed to the Middle Eastern Dust storms. Environ Sci Pollut Control Ser. 2017:1-9.
21. Neisi A, Vosoughi M, Idani E, et al. Comparison of normal and dusty day impacts on fractional exhaled nitric oxide and lung function in healthy children in Ahvaz, Iran. Environ Sci Pollut Control Ser. 2017;24:12360-12371.

22. Neisi A, Vosoughi M, Shirmardi M, et al. Concentration of air pollutants as toxic matter in urban and rural areas of Ahvaz. Toxin Rev. 2017:1-8.

23. Ackah M, Anim AK, Zakaria N, et al. Determination of some heavy metal levels in soft drinks on the Ghanaian market using atomic absorption spectrometry method. Environ Monit Assess. 2014;186:8499-8507.

24. Iwegbue CM. Concentrations of selected metals in candies and chocolates consumed in southern Nigeria. Food Addit Contam. 2011;4:22-27.

25. Järup L. Hazards of heavy metal contamination. Br Med Bull. 2003;68:167-182.

26. Liang Q, Xue Z-J, Wang F, Sun Z-M, Yang Z-X, Liu S-Q. Contamination and health risks from heavy metals in cultivated soil in Zhangjiakou City of Hebei Province, China. Environ Monit Assess. 2015;187:754.

27. Hajat S, Vardoulakis S, Heaviside C, Eggen B. Climate change effects on human health: projections of temperature-related mortality for the UK during the 2020s, 2050s and 2080s. J Epidemiol Community Health. 2014;68:641-648.

28. Kim K-H, Kabir E, Kabir S. A review on the human health impact of airborne particulate matter. Environ Int. 2015;74:136-143.

29. Taylor M, Retalis A, Flocas HA. Particulate matter estimation from photochemistry: a modelling approach using neural networks and synoptic clustering. Aerosol Air Qual Res. 2016;16:2067-2084.

30. Lin C-C, Tsai J-H, Huang K-L, et al. Characteristics of respirable particulate metals emitted by a beehive firework display in YanShuei area of southern Taiwan. Aerosol Air Qual Res. 2016;16:2227-2236.

31. Tchounwou PB, Yedjou CG, Patlolla AK, Sutton DJ. Heavy metal toxicity and the environment. Molecular, Clinical and Environmental Toxicology. Springer; 2012:133-164

32. Hou X, Strickland MJ, Liao K-J. Contributions of regional air pollutant emissions to ozone and fine particulate matter-related mortalities in eastern US urban areas. Environ Res. 2015;137:475-484.

33. Salvador P, Artíñano B, Viana M, Alastuey A, Querol X. Multicriteria approach to interpret the variability of the levels of particulate matter and gaseous pollutants in the Madrid metropolitan area, during the 1999-2012 period. Atmos Environ. 2015;109:205-216

34. Yan F, Winijkul E, Bond TC, Streets DG. Global emission projections of particulate matter (PM): II. Uncertainty analyses of on-road vehicle exhaust emissions. Atmos Environ. 2014:87:189-199.

35. Chan SH, Van Hee VC, Bergen S, et al. Long-term air pollution exposure and blood pressure in the sister study. Environ Health Perspect. 2015;123.

36. Ostro B, Hu J, Goldberg D, et al. Associations of mortality with long-term exposures to fine and ultrafine particles, species and sources: results from the California teachers study cohort. Environ Health Perspect. 2015;123:1-31.

37. Mammi-Galani E, Chalvatzaki E, Lazaridis M. Personal exposure and dose of inhaled ambient particulate matter bound metals in five European cities. Aerosol Air Qual Res. 2016;16:1452-1463.

38. Pope CA, Burnett RT, Turner MC, et al. Lung cancer and cardiovascular disease mortality associated with ambient air pollution and cigarette smoke: shape of the exposureâ€"response relationships. Environ Health Perspect. 2002;119:1616.

39. Lave LB, Seskin EP. Air Pollution and Human Health. Routledge; 2013.

40. Norval M, Lucas R, Cullen A, et al. The human health effects of ozone depletion and interactions with climate change. Photochem Photobiol Sci. 2011;10:199-225.

41. PAGE JP. Health effects of ozone. J Am Med Assoc. 2003;290.

42. Mraihi R, Harizi R, Mraihi T, Bouzidi MT. Urban air pollution and urban daily mobility in large Tunisia' s cities. Renew Sustain Energy Rev. 2015;43:315-320.

43. Peng RD, Butz AM, Hackstadt AJ, et al. Estimating the health benefit of reducing indoor air pollution in a randomized environmental intervention. J R Stat Soc Ser A 2015;178:425-443.

44. Pride KR, Peel JL, Robinson BF, et al. Association of short-term exposure to groundlevel ozone and respiratory outpatient clinic visits in a rural location-Sublette County, Wyoming, 2008-2011. Environ Res. 2015;137:1-7.

45. Raaschou-Nielsen O, Andersen ZJ, Beelen R, et al. Air pollution and lung cancer incidence in 17 European cohorts: prospective analyses from the European Study of Cohorts for Air Pollution Effects (ESCAPE). Lancet Oncol. 2013;14:813-822.

46. Woerman AL. Air Pollution \& Cardiovascular Disease. THE GEORGE WASHINGTON UNIVERSITY; 2013.

47. Gschwind B, Lefevre M, Blanc I, et al. Including the temporal change in PM 2.5 concentration in the assessment of human health impact: illustration with renewable energy scenarios to 2050. Environ Impact Assess Rev. 2015;52:62-68.

48. Madronich S, Shao M, Wilson S, Solomon K, Longstreth J, Tang X. Changes in air quality and tropospheric composition due to depletion of stratospheric ozone and interactions with changing climate: implications for human and environmental health. Photochem Photobiol Sci. 2015;14:149-169.

49. Taghavirad S, Davar H, Mohammadi M. The a study on concentration of BETX vapors during winter in the department of ports and shipping located in one of the southern cities of Iran. Int J Cur Life Sci. 2014;4:5416-5420.

50. Mašková L, Smolík J, Travnickova T, Havlica J, Ondráčková L, Ondráček J. Contribution of visitors to the indoor PM in the national library in prague, Czech republic. Aerosol Air Qual Res. 2016;16:1713-1721.

51. Andersen ZJ, de Nazelle A, Mendez MA, et al. A study of the combined effects of physical activity and air pollution on mortality in elderly urban residents: the Danish diet, cancer, and health cohort. Environ Health Perspect. 2015;123:25-32.

52. Kloog I, Nordio F, Zanobetti A, Coull BA, Koutrakis P, Schwartz JD. Short term effects of particle exposure on hospital admissions in the Mid-Atlantic states: a population estimate. PLoS One. 2014;9:e88578.

53. Mandel JH, Wendt C, Lo C, Zhou G, Hertz M, Ramachandran G. Ambient air pollution 
and lung disease in China: health effects, study design approaches and future research. Front Med. 2015;9:392-400.

54. Maleki H, Sorooshian A, Goudarzi G, Nikfal A, Baneshi MM. Temporal profile of PM 10 and associated health effects in one of the most polluted cities of the world (Ahvaz, Iran) between 2009 and 2014. Aeolian Res. 2016;22:135-140.

55. Gryparis A, Forsberg B, Katsouyanni K, et al. Acute effects of ozone on mortality from the â€œair pollution and health: a European approachâ€. Am J Respir Crit Care Med. 2004;170:1080-1087.

56. Frischer TM, Kuehr J, Pullwitt A, et al. Ambient ozone causes upper airways inflammation in children. Am Rev Respir Dis. 1993;148 961-961.

57. McClellan RO, Frampton MW, Koutrakis P, et al. Critical considerations in evaluating scientific evidence of health effects of ambient ozone: a conference report. Inhal Toxicol. 2009;21:1-36.

58. Goudarzi G, Zallaghi E, Neissi A, et al. Cardiopulmonary mortalities and chronic obstructive pulmonary disease attributed to ozone air pollution. Arch Hyg Sci. 2013;2:62-72.

59. Pride KR, Peel JL, Robinson BF, et al. Association of short-term exposure to groundlevel ozone and respiratory outpatient clinic visits in a rural location - sublette County, Wyoming, 2008-2011. Environ Res. 2015;137:1-7.

60. Tsai S-S, Goggins WB, Chiu H-F, Yang C-Y. Evidence for an association between air pollution and daily stroke admissions in Kaohsiung, Taiwan. Stroke. 2003;34:2612-2616.

61. Zallaghi E, Goudarzi G, Haddad MN, Moosavian SM, Mohammadi MJ. Assessing theEffects of nitrogen dioxide in urban air on health of west and southwest cities of Iran. Jundishapur J Health Sci. 2014;6:e23469.

62. Barnett AG, Williams GM, Schwartz J, et al. The effects of air pollution on hospitalizations for cardiovascular disease in elderly people in Australian and New Zealand cities. Environ Health Perspect. 2006;114:1018.

63. Dockery DW, Pope CA, Xu X, et al. An association between air pollution and mortality in six US cities. $N$ Engl $J$ Med. 1993;329:1753-1759.

64. Mohammadi M. Studied hygienic effects of air pollution in town Ahvaz in 2009 with model Air Q. Nat Conf Air Pollut. 2009.

65. Zalaghi E. Survey of Health Effects of Air Pollution Ahvaz, Bushehr and Kermanshah with Use of AIRQ Model MSc Thesis Ahvaz: Islamic Azad University, Science and Research Branch; 2010.

66. Bell ML, McDermott A, Zeger SL, Samet JM, Dominici F. Ozone and short-term mortality in 95 US urban communities, 1987-2000. JAMA. 2004:292:2372-2378.

67. Glad JA, Brink LL, Talbott EO, et al. The relationship of ambient ozone and PM2. 5 levels and asthma emergency department visits: possible influence of gender and ethnicity. Arch Environ Occup Health. 2012;67:103-108.

68. Rich DQ, Mittleman MA, Link MS, et al. Increased risk of paroxysmal atrial fibrillation episodes associated with acute increases in ambient air pollution. Environ Health Perspect. 2006:120-123.

69. Labelle R, Brand A, Buteau S, Smargiassi A. Hospitalizations for respiratory problems and exposure to industrial emissions in children. Environ Pollut. 2015;4:77.
70. Lippmann M, Ito K, Nadas A, Burnett R. Association of Particulate Matter Components with Daily Mortality and Morbidity in Urban Populations Research report Health Effects Institute; 2000 discussion 73-82.

71. Hassani GBA, Takdastan A, Shirmardi M, Yousefian F, Mohammadi MJ. Occurrence and fate of $17 \beta$-estradiol in water resources and wastewater in Ahvaz, Iran. Glob NEST J. 2016;18:855-866.

72. Mohammadi MJ, Takdastan A, Jorfi S, et al. Electrocoagulation process to Chemical and Biological Oxygen Demand treatment from carwash grey water in Ahvaz megacity, Iran. Data in Brief. 2017;11:634-639.

73. Niri MV, Mahvi AH, Alimohammadi M, et al. Removal of natural organic matter (NOM) from an aqueous solution by $\mathrm{NaCl}$ and surfactant-modified clinoptilolite. $J$ Water Health. 2015;13:394-405.

74. Zallaghi E, Goudarzi G, Geravandi S, Javad M. Epidemiological indexes attributed to particulates with less than 10 micrometers in the air of ahvaz city during 2010 to 2013. Health Scope. 2014;3.

75. Geravandi S, Neisi A, Goudarzi G, Vousoghi Niri M, Mohammadi M. Estimation of cardiovascular and respiratory deaths related to ozone exposure in ahvaz, during 2011. J Rafsanjan Univ Med Sci. 2015;13:1073-1082.

76. Nelson SD, Malone D, Lafleur J. Calculating the baseline incidence in patients without risk factors: a strategy for economic evaluation. PharmacoEconomics. 2015;33(39):887-892.

77. Goudarzi G, Geravandi S, Mohammadi MJ, Salmanzadeh S, Vosoughi M, Sahebalzamani M. The relationship between air pollution exposure and chronic obstructive pulmonary disease in Ahvaz, Iran. Chronic Dis J. 2015;3.

78. Goudarzi GR, Geravandi S, Salmanzadeh S, Mohammadi MJ. An estimation of respiratory deaths and COPD related to SO2 pollutant in Tabriz, northwest of Iran (2011). Razi J Med Sci. 2015;22:44-50.

79. Mohammadi MJ, Godini H, Khak MT, Daryanoosh SM, Dobaradaran S, Goudarzi G. An association between air quality and COPD in ahvaz, Iran. Jundishapur J Chronic Dis Care. 2015;4.

80. Organization WH. ICD-10: International Statistical Classification of Diseases and HealthRelated Problems. vol. 10. Geneva: WHO; 2010:64-67.

81. Middleton N. Desert dust hazards: a global review. Aeolian Res. 2017;24:53-63.

82. Burnett RT, Smith-Doiron M, Stieb D, Cakmak S, Brook JR. Effects of particulate and gaseous air pollution on cardiorespiratory hospitalizations. Arch Environ Health. 1999;54:130-139.

83. Geravandi S, Goudarzi G, Vosoughi M, javad Mohammadi M, Salmanzadeh S, Zallaghi E. Relationship between Particulate matter less than 10 microns exposures and health effects on humans in Ahvaz, Iran. Arch Hyg Sci. 2015;4.

84. Biggeri A, Bellini P, Terracini B, Italian MG. [Meta-analysis of the Italian studies on short-term effects of air pollution]. Epidemiol Prev. 2001;25:1-71.

85. Shavrina A, Mikulskaya I, Kiforenko S, Sheminova V, Veles A, Blum O. The Study of Ground-Level Ozone in Kiev and its Impact on Public Health. 2012; 2012 arXiv preprint arXiv:1204.1902. 